\title{
Tuberculosis in Juvenile Idiopathic arthritis under Anti-TNF therapy
}

\author{
G Espada*, J Giupponi, C Cerqueiro \\ From 18th Pediatric Rheumatology European Society (PReS) Congress \\ Bruges, Belgium. 14-18 September 2011
}

Tuberculosis (TB) is still a prevalent disease, one third of the population is infected by mycobacterium tuberculosis $(M T)$.Treatment with anti TNF therapies appears to increase the risk for developing $\mathrm{TB}$

\section{Aim}

to study the occurrence of latent TB (LTB) or tuberculosis disease (TBD) in children with JIA under anti TNF therapy.

\section{Methods}

Clinical records from pts with JIA ( ILAR'01) under anti-TNF therapy were reviewed, focusing on TB screening prior to biologicals, PPD conversion or TBD diagnosiss.LTB was considered as a PPD (TST) positive $(\geq 5 \mathrm{~mm}$ ), in the abscense of radiological manifestations of TB.

\section{Results}

105 JIA pts received one or more anti TNF drugs during the observation. Four of them developed LTB and 3 others TBD.
No extrapulmonar TB or miliary forms were observed. All patients were PPD negative prior to biological agents

\section{Conclusions}

No significative difference was found between specific anti TNF and the occurrence of LTB or TBD. In 4 pts, the infectious event occurred after 2 ys of exposure and in two earlier as described in the literature. This data highlights the importance of $\mathrm{TB}$ surveillance prior to and during anti-TNF therapy.

Published: 14 September 2011

doi:10.1186/1546-0096-9-S1-P72

Cite this article as: Espada et al:: Tuberculosis in Juvenile Idiopathic arthritis under Anti-TNF therapy. Pediatric Rheumatology 2011 9(Suppl 1): P72.

Table

\begin{tabular}{|c|c|c|c|c|c|c|c|c|}
\hline & Gender/ age( ys) & Dx & $\mathrm{PPD}(\mathrm{mm})^{*}$ & TBDisease & antiTNF & Time under 1st Biologic & TB tx & 2nd Biological Tx \\
\hline Pt 1 & $M / 18$ & $\mathrm{pJlA}$ & 18 & no & ETN & $24 \mathrm{~m}$ & $\mathrm{INH}$ & No \\
\hline Pt 2 & $F / 20$ & OJlA & 12 & no & ADA & $24 \mathrm{~m}$ & $\mathrm{INH}$ & No \\
\hline Pt 3 & $F / 7$ & $\mathrm{pJlA}$ & 6 & no & ETN & $11 \mathrm{~m}$ & $\mathrm{INH}$ & INF \\
\hline Pt 4 & $M / 13$ & sJIA & 13 & no & IFX & $1 \mathrm{~m}$ & $\mathrm{INH}$ & No \\
\hline Pt 5 & $\mathrm{~F} / 14$ & pllA & 10 & Pulmonar involvement & IFX & $6 \mathrm{~m}$ & 4 drugs & ETN \\
\hline Pt 6 & $\mathrm{~F} / 17$ & $\mathrm{pJlA}$ & 13 & Pulmonar involvement & IFX & $24 \mathrm{~m}$ & 4 drugs & No \\
\hline Pt 7 & $\mathrm{~F} / 12$ & pJIA & 13 & Pulmonar involvement & ETN & $30 \mathrm{~m}$ & 4 drugs & ETN \\
\hline
\end{tabular}

Rheumatology and Tisiology Sections, Hospital de Niños, Dr Ricardo

Gutierrez, Buenos Aires, Argentina

B- Central 2011 Espada et al; licensee BioMed Central Ltd. This is an open access article distributed under the terms of the Creative Commons
Attribution License (http://creativecommons.org/licenses/by/2.0), which permits unrestricted use, distribution, and reproduction in
any medium, provided the original work is properly cited. 